Research Article

\title{
Loading Rate Effect of Rock Material with the Direct Tensile and Three Brazilian Disc Tests
}

\author{
Fengqiang Gong $\mathbb{D},{ }^{1}$ Le Zhang $\mathbb{D}^{1},{ }^{1}$ and Shanyong Wang ${ }^{2}$ \\ ${ }^{1}$ School of Resources and Safety Engineering, Central South University, Changsha, Hunan 410083, China \\ ${ }^{2}$ ARC Centre of Excellence for Geotechnical Science and Engineering, Faculty of Engineering and Built Environment, \\ The University of Newcastle, University Drive, Callaghan, NSW 2308, Australia
}

Correspondence should be addressed to Fengqiang Gong; fengqiangg@126.com

Received 18 September 2018; Accepted 13 February 2019; Published 10 March 2019

Academic Editor: Raffaele Landolfo

Copyright (c) 2019 Fengqiang Gong et al. This is an open access article distributed under the Creative Commons Attribution License, which permits unrestricted use, distribution, and reproduction in any medium, provided the original work is properly cited.

\begin{abstract}
A series of experimental tests were conducted to investigate the effects of loading rate on the tensile strength of sandstone by using four test methods, including a direct tensile method and three typical Brazilian disc methods (plate loading, circular arc loading, and strip loading). The loading rates used in these tests varied from $10^{-2} \mathrm{MPa} / \mathrm{s}$ to $10^{0} \mathrm{MPa} / \mathrm{s}$. The results show that the rate effects are clear for these test methods, and the tensile strength of sandstone will increase linearly with the logarithm of the loading rate. At the same loading rate, it is found that the tensile strengths of the sandstone specimens under plate loading and arc loading are relatively similar and are much greater than the direct tensile strength, while the tensile strength under strip loading is less than the direct strength. A comprehensive comparison suggested that the strip loading method can be adopted for the Brazilian disc test, while the obtained strength should be modified with a coefficient of 1.37 to obtain the direct tensile strength.
\end{abstract}

\section{Introduction}

As is well known, tensile failure is one of the most common failure modes of rock materials, and the stability of rock structures usually depends on their tensile strength [1]. In experimental research of rock materials, the direct tensile test is considered the most effective method for determining rock tensile strength [2-5]. However, due to the difficulty of specimen processing and pure one-dimensional direct tensile loading, the Brazilian disc test was introduced and used widely to determine the indirect tensile strength of rock or rock-like materials $[3,4,6,7]$, which has been accepted by many researchers [8-13] or test standards [14-16] because of its simplicity and ease of operation. In Brazilian disc tests, three sets of loading methods, including the strip loading method, the circular arc loading method, and the plate loading method, were usually adopted to measure the indirect tensile strength of rock materials [17]. To identify the tensile strength of rock under different contact conditions, numerical calculations and experimental investigations were conducted $[3,4,8,18,19]$. The existing investigations provided a comprehensive reference for testing the tensile strength of rock in geotechnical engineering to a certain extent [20-25]. Furthermore, the results of many tensile tests showed that the tensile strength of rock exhibits a clear loading rate effect, i.e., the tensile strength increases with the loading rate $[20,24]$. However, from the investigations, only one or two loading methods were qualitatively compared at a given loading rate, and the conclusions were applicable only in particular cases. Zhao et al [26] conducted Brazilian disc tests with five loading rates, and the testing results showed that the tensile strength of rock increases logarithmically with the increase in loading rate. In addition, tensile tests with different loading rates were performed on granite by Zhao and $\mathrm{Li}$ [27] who found that when the strain rate is in the range of $10^{-1} \sim 10^{2} \mathrm{MPa} / \mathrm{s}$, the tensile strength of the granite will increase by approximately $10 \%$ when the strain rate increases by one order of magnitude. In this paper, the loading rate effects under different loading methods were studied based on the previous research. In addition, the 
Brazilian disc test (under plate loading, circular arc loading, and strip loading) and direct tensile test, at the loading rates of $0.001 \mathrm{~mm} / \mathrm{s}, 0.01 \mathrm{~mm} / \mathrm{s}, 0.1 \mathrm{~mm} / \mathrm{s}$, and $1 \mathrm{~mm} / \mathrm{s}$, were carried out on red sandstone using the MTS-Landmark testing system and the universal testing machine WDW$100 \mathrm{E}$, respectively.

\section{Testing Methods and Devices}

2.1. Specimen Preparation. All specimens were collected from the same piece of unweathered homogeneous red sandstone block. The specimens prepared for the direct tensile testing were cylinders with a height: diameter ratio of $2: 1$, and the height: diameter ratio of the Brazil disk specimens was $1: 2$. The smoothness of the two end faces of each specimen met the accuracy requirements of the ISRM, and all the specimens had natural moisture content. The average naturally dried density of the processed specimens is $2463.04 \mathrm{~kg} / \mathrm{m}^{3}$ (the variation coefficient is 0.008 ). In addition, the average value of the uniaxial compressive strength of the specimens is $100 \mathrm{MPa}$, which indicates that this kind of red sandstone is a typical hard rock.

2.2. Direct Tensile Method and Device. To carry out the direct tensile test, the bond and centring device (see Figure 1) was used in this research $[28,29]$. This device can effectively solve the eccentric problem of the rock specimens. In the test, high-strength resin adhesive was used to bond the pull head and rock specimen together, and the bonding strength of the bonding interface between the specimen and pull head is up to $15 \mathrm{MPa}$, which meets the testing requirements. It is worth noting that the adhesive layer should be uniform with a thickness in the range of $0.8 \sim 1 \mathrm{~mm}$. The pull head is connected to the ball hinge through a T-slider.

The direct tensile device in the WDW-100E universal testing machine is shown in Figure 2. The direct tensile strength $\sigma_{\mathrm{t}}^{\mathrm{d}}(\mathrm{MPa})$ can be calculated by the following formula:

$$
\sigma_{\mathrm{t}}^{\mathrm{d}}=\frac{4 P_{\mathrm{d}}}{\pi D^{2}}
$$

where $P_{\mathrm{d}}$ is the maximum load during loading $(N)$ and $D$ is the diameter of the specimen $(\mathrm{mm})$.

2.3. Indirect Tensile Method and Device. The indirect tensile strength $\sigma_{\mathrm{t}}^{\mathrm{i}}$ of rock in the Brazilian disc test can be expressed by

$$
\sigma_{\mathrm{t}}^{\mathrm{i}}=\frac{2 P_{\mathrm{b}}}{\pi D H}
$$

where $P_{\mathrm{b}}$ is the maximum load during loading $(N), D$ is the diameter of the specimen ( $\mathrm{mm})$, and $H$ is the thickness of the specimen $(\mathrm{mm})$.

Figures 3 and 4 show the three loading devices commonly used in Brazilian disc tests for rock materials. All the tests, under the three loading methods, were carried out on the MTS test machine, as shown in Figure 5.

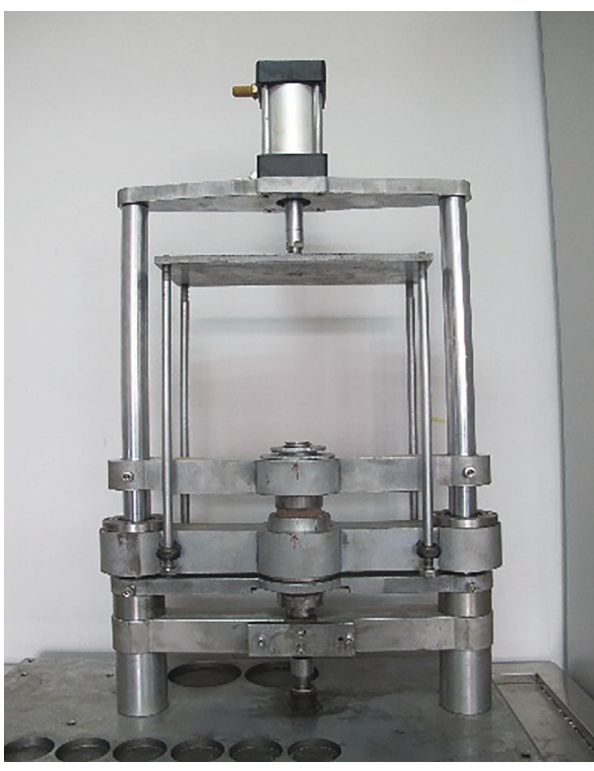

FIgURE 1: Bond centring device.

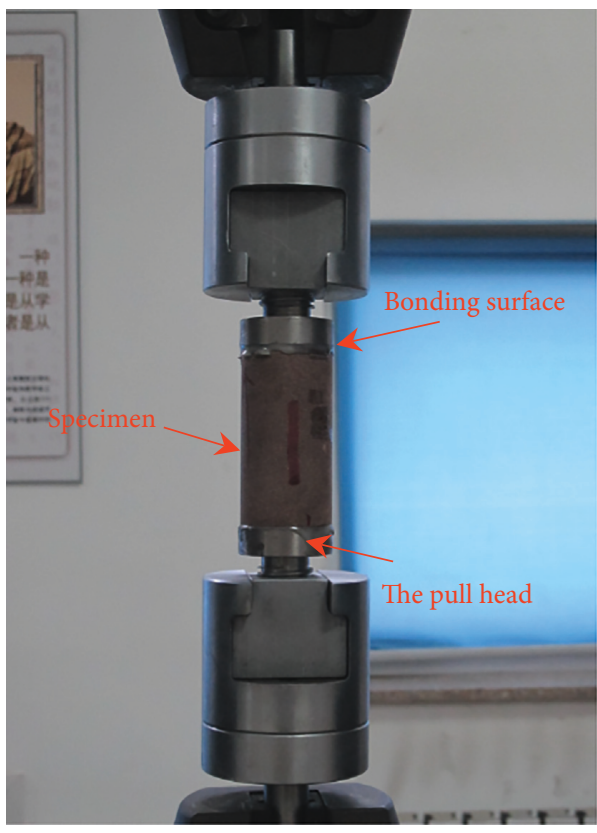

Figure 2: Direct tension test device.

\section{Test Results}

3.1. Results of the Direct Tensile Test. To study the effect of different loading rates on the tensile strength of sandstone, the displacement control loading mode was adopted in the test, and the direct tensile tests were carried out at the loading rates of $0.001 \mathrm{~mm} / \mathrm{s}, 0.01 \mathrm{~mm} / \mathrm{s}, 0.1 \mathrm{~mm} / \mathrm{s}$, and $1 \mathrm{~mm} / \mathrm{s}$. In addition, the physical and mechanical parameters of the specimens are shown in Table 1.

Figure 6 shows the stress-strain curves of direct tensile tests under four different loading rates; combined with Table 1, Figure 6 shows that with an increase in the loading rate, the strain and stress of the specimen both increase and 


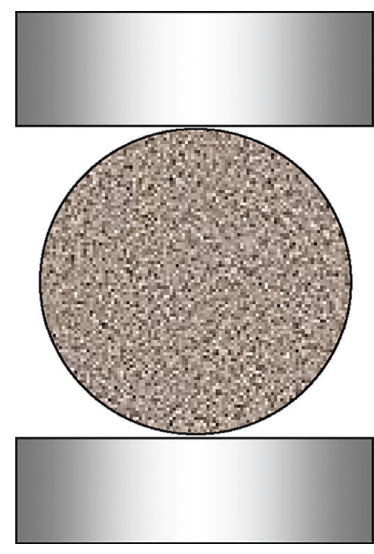

(a)

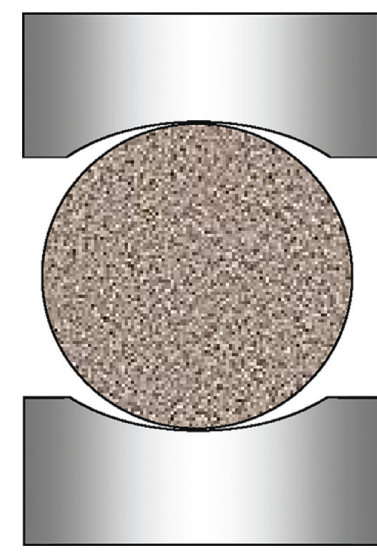

(b)

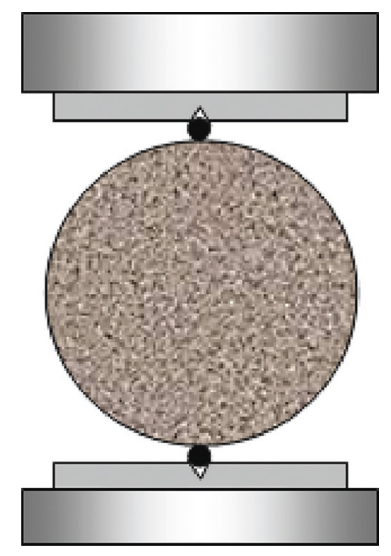

(c)

Figure 3: Three typical Brazilian disc test loading methods. (a) Plate loading. (b) Circular arc loading. (c) Strip loading.

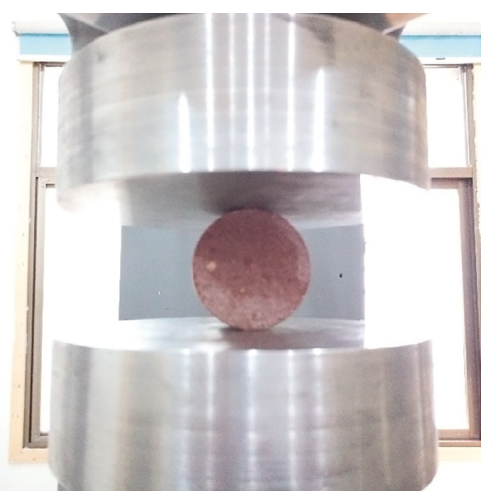

(a)

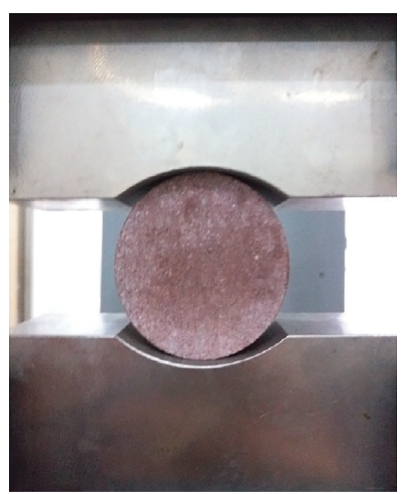

(b)

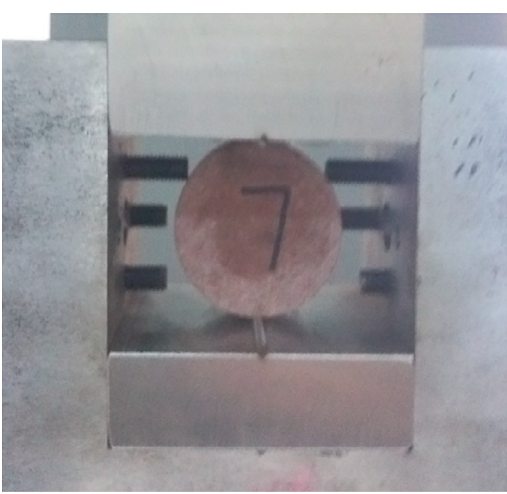

(c)

FIgURE 4: Three typical loading devices of the Brazilian disc test installed in the MTS-Landmark testing system. (a) The plate loading device. (b) The circular arc loading device. (c) The strip loading device.

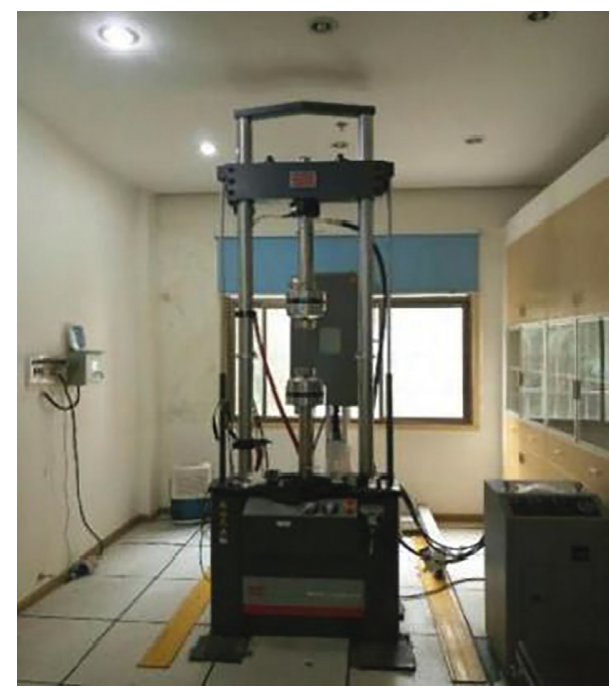

FIgURE 5: The MTS-Landmark testing system.

exhibit a pronounced loading rate effect. Specifically, when the loading rate is $0.001 \mathrm{~mm} / \mathrm{s}$, the tensile stress is $3.57 \mathrm{MPa}$, and the tensile strain is $7.86 \times 10^{-3}$; when the loading rate increases from $0.01 \mathrm{~mm} / \mathrm{s}$ to $1 \mathrm{~mm} / \mathrm{s}$, the tensile stress increases from $4.16 \mathrm{MPa}$ to $4.66 \mathrm{MPa}$, an increase of $16.52 \%$, $22.12 \%$, and $30.53 \%$ for the higher tested strain rates. Additionally, the tensile strain is $8.62 \times 10^{-3}, 9.1 \times 10^{-3}$, and $9.75 \times 10^{-3}$, which are increases of $9.66 \%, 15.77 \%$, and $24.04 \%$, respectively. When the stress reaches the peak strength of the specimen, the specimen suddenly loses its stability and exhibits a typical brittle fracture.

Figure 7 describes the direct tensile failure mode of a sandstone specimen, the fracture surface forms in the main part of the specimen, and the bond between the pull head and specimen does not peel off. Therefore, it is reasonable to consider that the tensile strength of the specimen can be accurately reflected by the test result.

3.2. Result of the Indirect Tensile Test. Like the direct tensile test, the displacement control loading method was employed to conduct the Brazilian disc test. To analyse the influence of the different loading methods and loading rates on the results of the indirect tensile tests of the rock specimens, three groups of loading methods were adopted, including strip loading, plate loading, and arc loading. Furthermore, 
TABLE 1: Test parameters for the direct tensile test specimens.

\begin{tabular}{lccccccc}
\hline No & $D(\mathrm{~mm})$ & $H(\mathrm{~mm})$ & $\rho\left(\mathrm{kg} / \mathrm{m}^{3}\right)$ & $v(\mathrm{~mm} / \mathrm{s})$ & $\varepsilon\left(10^{-3}\right)$ & $\sigma(\mathrm{MPa})$ & $\dot{\sigma} \log (\mathrm{MPa} / \mathrm{s})$ \\
\hline $2-1$ & 48.73 & 100.43 & 2423.87 & 0.001 & 7.86 & 3.57 & -2.35 \\
$2-3$ & 48.73 & 101.02 & 2436.25 & 0.01 & 8.62 & 4.16 & -1.32 \\
$2-4$ & 48.73 & 100.48 & 2428.01 & 0.1 & 9.10 & 4.36 & -0.36 \\
$2-6$ & 48.73 & 99.93 & 2435.99 & 1 & 9.75 & 4.66 & 0.67 \\
\hline
\end{tabular}

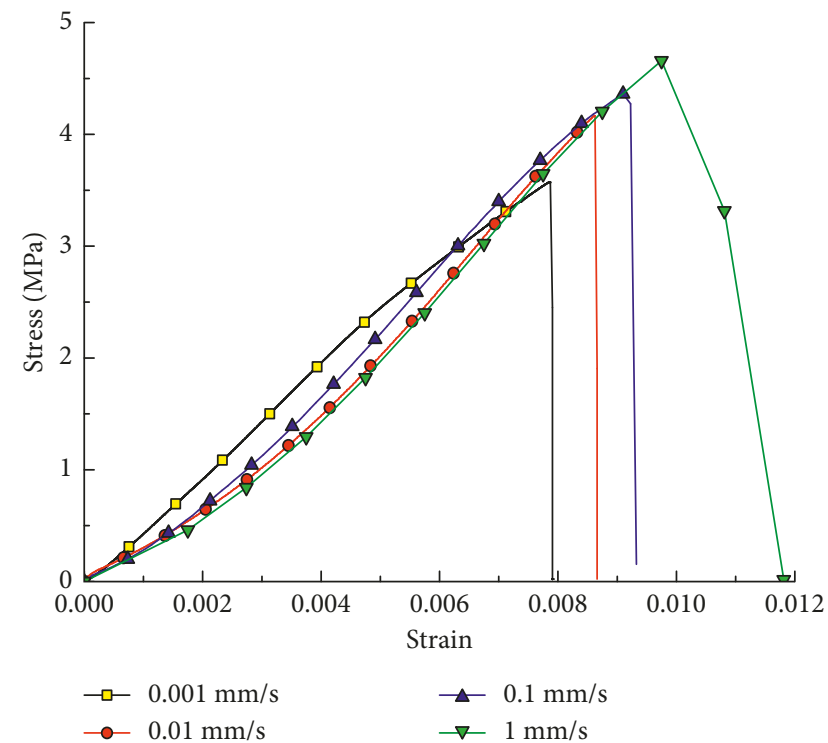

FIGURE 6: Stress-strain curves of the specimens under different loading rates.

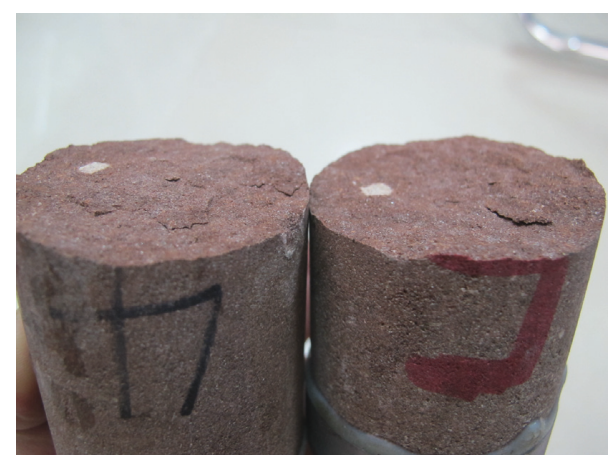

Figure 7: Specimen failure mode in direct tensile test.

different loading rates $(0.001,0.01,0.1$, and $1 \mathrm{~mm} / \mathrm{s})$ were evaluated for each loading method. The physical and mechanical parameters of the specimens under these three loading methods are listed in Table 2.

As seen from Figure 8, the load-displacement curves of specimens under strip loading vary at high loading rates and become smoother as the loading rate decreases. This result is because the strip loading generated a kind of linear load, and vibrations may occur during the loading process. Since the sandstone is a hard brittle rock, the postpeak section of the load-displacement curve suddenly decreases under strip loading and is synchronously accompanied by a crisp sound. From Table 2, it can be found that the Brazilian disc strength $\sigma_{\text {ts }}^{\mathrm{i}}$ under strip loading has a significant rate effect, i.e., the tensile strength increased from 2.79 $\mathrm{MPa}$ to $3.61 \mathrm{MPa}$ when the loading rate increased from $0.008 \mathrm{MPa} / \mathrm{s}$ to $8.163 \mathrm{MPa} / \mathrm{s}$; there is a total tensile strength increase of $13.3 \%$.

Figure 9 shows the fracture failure modes of specimens No. 1-24 and No. 1-26 under strip loading. It can be observed that the two specimens are destroyed by failure across the diameter of their circular end faces; eventually, a thin, approximately linear, main crack is produced on the end face. However, it is difficult to observe the secondary crack near the main crack in Figure 9. Since the specimen was subject to a linear load during the Brazilian disc test under the strip loading method, the strip (extender) was pressed into the crushing zone after the peak strength of the specimen had been reached, resulting in the formation of a small damage zone at the loading end of the specimen, creating a very small $\mathrm{V}$-shaped groove. With the increase of the loading rate, the failure mode of the specimen has not changed.

Figure 10 illustrates the load-displacement curves of specimens under plate loading. The curves do not comprise a plastic deformation segment (or the segment is negligible), and an elastic deformation segment is presented before the destruction of the specimen; thus, it follows the typical failure mode of brittle rock. Based on the data in Table 2, the indirect tensile strength $\sigma_{\text {tp }}^{\mathrm{i}}$ under plate loading also has a clear rate effect. When the loading rate increases from $0.024 \mathrm{MPa} / \mathrm{s}$ to $17.487 \mathrm{MPa} / \mathrm{s}$, the tensile strength increases from $6.13 \mathrm{MPa}$ to $7.34 \mathrm{MPa}$, with a total increase of $17.3 \%$.

Figure 11 shows the failure modes of specimens No. 1-11 and No. 1-12 under plate loading. As seen from Figure 11, the initial main crack, which is approximately straight in the photo, developed along the central axis of the specimens. Unlike for the earlier mentioned specimen failure under strip loading, after the initial main crack was generated under plate loading, the secondary cracks occurred near the initial main crack at the loading end of the specimen and gradually propagated to the initial main crack, causing a larger main crack on the axis of the specimen. Additionally, the obvious deep V-shaped grooves appeared at the loading end of the specimen, unsimilar to that under strip loading. With the increase of the loading rate, there are more and more cracks in the specimen, and there is an increasing trend in the area of destruction.

Figure 12 shows the load-displacement curves of the specimens by employing the arc loading method. These load-displacement curves can be classified into three sections: the initial compression section, the elastic loading section, and the postpeak deformation section. Due to the fixed effect of the arc, the specimen continued to exhibit the ability to bear load and to deform after its peak strength was 
TABle 2: Parameters of the specimens from the indirect tensile tests.

\begin{tabular}{|c|c|c|c|c|c|c|c|}
\hline Method & No & $D(\mathrm{~mm})$ & $H(\mathrm{~mm})$ & $\rho\left(\mathrm{kg} / \mathrm{m}^{3}\right)$ & $v(\mathrm{~mm} / \mathrm{s})$ & $\sigma(\mathrm{MPa})$ & $\dot{\sigma}(\mathrm{MPa} / \mathrm{s})$ \\
\hline \multirow{4}{*}{ Strip loading } & $1-2$ & 48.3 & 25.66 & 2446.01 & 0.001 & 2.79 & 0.008 \\
\hline & $1-26$ & 48.3 & 25.40 & 2449.55 & 0.01 & 2.85 & 0.087 \\
\hline & $1-23$ & 48.3 & 25.33 & 2434.77 & 0.1 & 3.12 & 0.841 \\
\hline & $1-24$ & 48.3 & 25.91 & 2485.59 & 1 & 3.61 & 8.163 \\
\hline \multirow{4}{*}{ Plate loading } & $1-11$ & 48.3 & 25.66 & 2424.73 & 0.001 & 6.13 & 0.024 \\
\hline & $1-12$ & 48.3 & 25.98 & 2457.89 & 0.01 & 6.41 & 0.243 \\
\hline & $1-13$ & 48.3 & 25.86 & 2469.29 & 0.1 & 6.78 & 2.099 \\
\hline & $1-28$ & 48.3 & 24.96 & 2470.87 & 1 & 7.34 & 17.487 \\
\hline \multirow{4}{*}{ Arc loading } & $1-16$ & 48.3 & 25.65 & 2489.51 & 0.001 & 6.27 & 0.014 \\
\hline & $1-17$ & 48.3 & 25.73 & 2460.56 & 0.01 & 6.55 & 0.157 \\
\hline & $1-18$ & 48.3 & 25.15 & 2452.20 & 0.1 & 7.15 & 1.606 \\
\hline & $1-20$ & 48.3 & 25.86 & 2469.29 & 1 & 7.27 & 13.778 \\
\hline
\end{tabular}

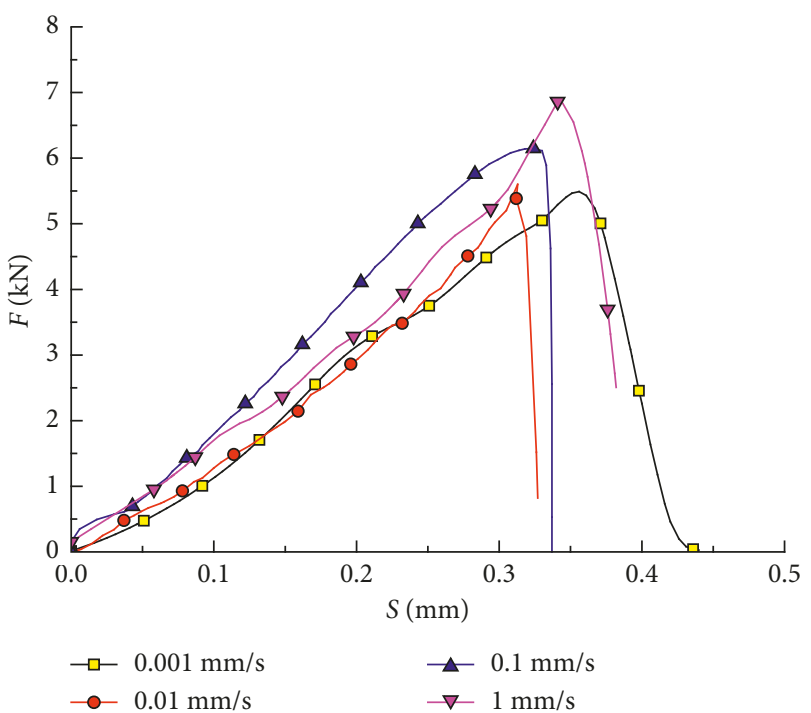

Figure 8: Load-displacement curves of specimens under strip loading.

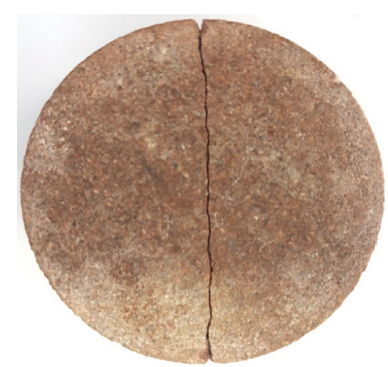

(a)

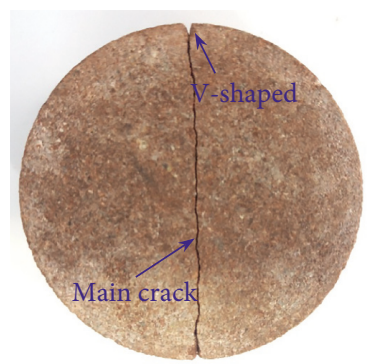

(b)
Figure 9: The typical failure mode of the specimens under strip loading. (a) No. 1-26. (b) No. 1-24.

reached. The results in Table 2 are similar to the indirect tensile strength based on the other two loading methods; the tensile strength $\sigma_{\text {tc }}^{\mathrm{i}}$ of specimen under arc loading has a clear loading rate effect, i.e., when the loading rate increases from $0.014 \mathrm{MPa} / \mathrm{s}$ to $13.778 \mathrm{MPa} / \mathrm{s}$, the tensile strength increases from $6.27 \mathrm{MPa}$ to $7.27 \mathrm{MPa}$, a total increase of $15.95 \%$.

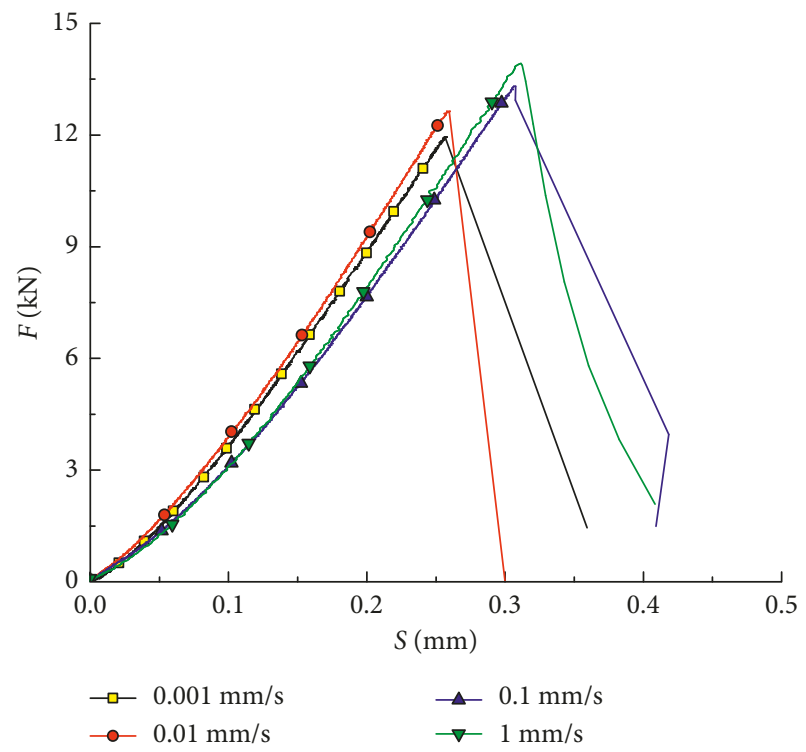

FIGURE 10: Load-displacement curves of specimens under plate loading.

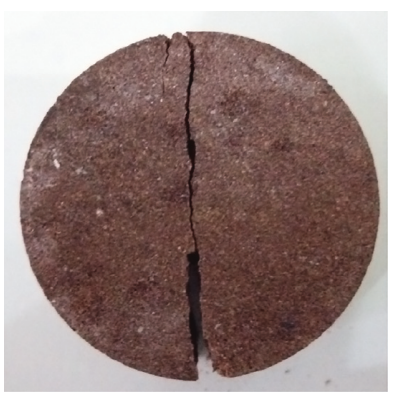

(a)

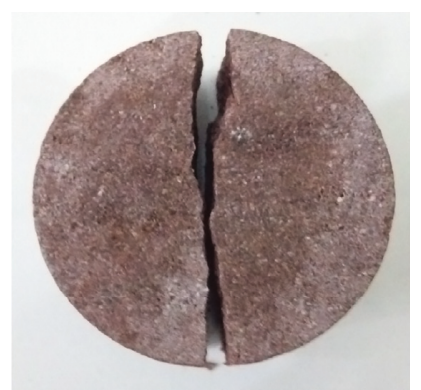

(b)
FIgURE 11: The failure mode of specimens under plate loading. (a) No. 1-11. (b) No. 1-12.

Figure 13 shows photographs of specimens No. 1-17 and No. 1-18, which were subjected to arc loading. The main crack is located at the centre of the specimen along the diameter, which is similar to the damage observed under the strip loading and plate loading. Because of the fixed effect of 


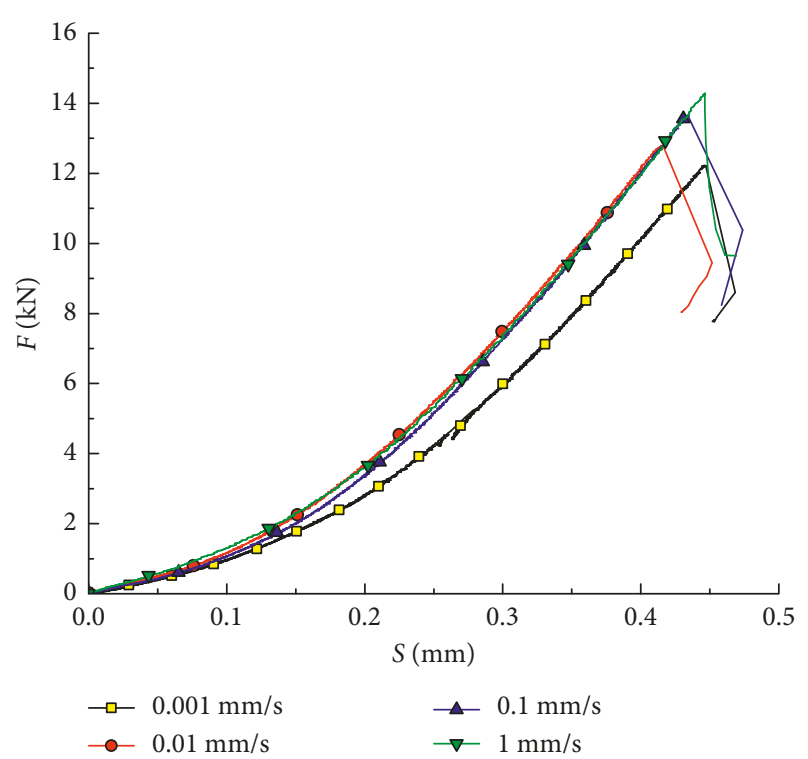

Figure 12: Load-displacement curves of specimens under arc loading.

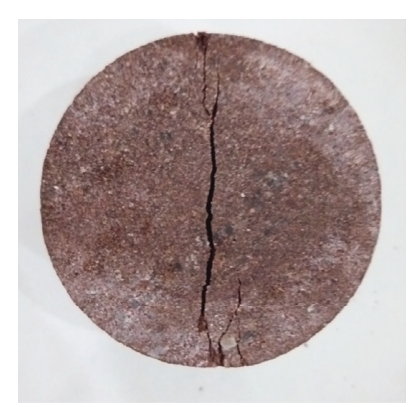

(a)

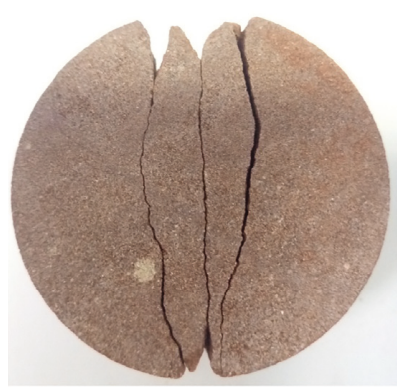

(b)
Figure 13: Failure of specimens No. 1-17 (a) and No. 1-18 (b) under arc loading.

the arc loading, the specimen does not suddenly lose its stability as the linear load reaches its peak strength but continues to deform as a whole. When the main crack propagates through the specimen, numerous secondary cracks form around the main crack. These cracks, which are the main deformation features during the postpeak stage of the specimen, are gradually developed, and a new fracture area is formed around the main crack. Similar to the results from the plate loading method, with the increase of the loading rate, more and more cracks appeared in the loading contact area of the specimen, and the scope of destruction is getting bigger and bigger.

Comparing Figures 9, 11, and 13, it can be seen that the specimens in Figure 9 can still be well spliced after they break in half, and the failure mode is not affected by loading rate. In Figures 11 and 13, there are some secondary cracks in the specimen after the tests, and the secondary cracks become more and more obvious with the increase of loading rate. The above comprehensive comparison shows that the central area of the sample can reach the ideal tensile stress under the strip loading.

\section{Discussions}

In our experiments, the tensile strength of sandstone under arc loading is the largest, followed by that under plate loading, and the strength under strip loading is the minimum. In addition, the direct tensile strength is the intermediate strength compared with the strengths under arc loading and strip loading. This is because arc loading is similar to plate loading; the local compression limits the expansion of the zone of tension during the loading process and thus requires a greater vertical force. During the strip loading, the tensile crack propagation is accelerated, and the vertical force is reduced due to the local expansion of the wedge-shaped area. Many scholars have also given different viewpoints on how to characterize the tensile strength of rocks by using the indirect tensile test method and direct tensile test method. A comparison of the rock strengths, which were measured under arc loading, plate loading, and direct loading, has been conducted by Zhang et al [18]; the results show that the measured strengths under arc loading can be used as the upper limit of the tensile strength, and the strengths measured under strip loading can be used as the lower limit. The above analysis in this paper shows that the experimental results are clearly consistent with those of Zhang et al [18].

In order to find a relatively accurate method to estimate the uniaxial tensile strength using the indirect tensile test, the tensile strengths under four loading methods (plate loading, arc loading, strip loading, and direct tensile loading) were compared and analysed (see Figure 14; the tensile test results of another red sandstone are given in reference [20]). Figure 14 shows that although there is a considerable difference among those three indirect tensile strengths, the tensile strengths obtained from the three loading methods can be used to estimate the direct tensile strength within certain accuracy.

As indicated in Figure 14, a comparative analysis of the different loading rate effects on the sandstone strength under the four loading methods was first performed. Then, the slope $a$, intercept $B$, and the fitting coefficient $R^{2}$ of the fitted lines were simultaneously obtained, and the deviations of the slopes of the fitted lines under the four loading methods were determined (shown in Table 3).

Compared with the other two indirect loading methods, it can be clearly seen that the strengths measured form the strip loading tests and direct tensile tests are similar. The slopes of the fitted lines under strip loading and direct tension are 0.275 and 0.345 , respectively. The deviation of slope under strip loading, which is $20.29 \%$, is the smallest from the three indirect tensile methods when the three slopes are compared with that under direct loading. In addition, the slope of the fitted line under plate loading is close to that under strip loading, and the strengths from these two tests can be considered the upper and lower limits of the uniaxial tensile strength. On the other hand, the strengths under plate loading and arc loading are larger than those under strip loading, causing a considerable error when only one of the strengths measured from the three loading methods is used to estimate the uniaxial tensile strength of rock.

From the above analysis, combined with the failure modes of the indirect tensile specimens from the three kinds 


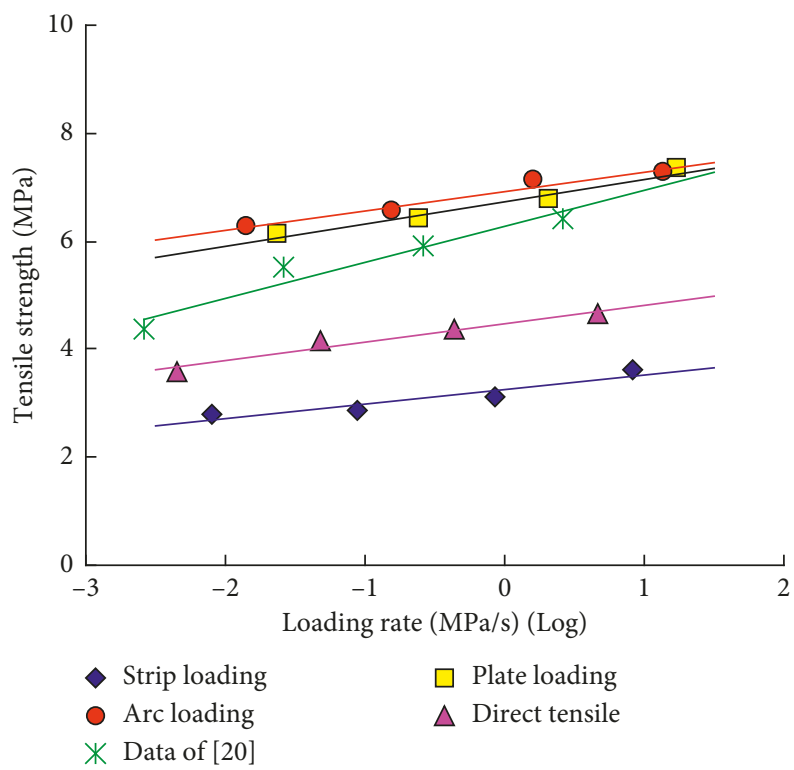

Figure 14: Comparison of sandstone tensile strengths under different loading methods.

TABLE 3: Comparison of the indirect tensile strength and direct tensile strength under different loading methods.

\begin{tabular}{lccccccc}
\hline $\log ($ loading rate $)(\mathrm{MPa} / \mathrm{s})$ & $\sigma_{\mathrm{t}}^{\mathrm{d}}(\mathrm{MPa})$ & $\sigma_{\mathrm{tc}}^{\mathrm{i}}(\mathrm{MPa})$ & $\sigma_{\mathrm{tp}}^{\mathrm{i}}(\mathrm{MPa})$ & $\sigma_{\mathrm{ts}}^{\mathrm{i}}(\mathrm{MPa})$ & $\sigma_{\mathrm{t}}^{\mathrm{d}} / \sigma_{\mathrm{tc}}^{\mathrm{i}}$ & $\sigma_{\mathrm{t}}^{\mathrm{d}} / \sigma_{\mathrm{tp}}^{\mathrm{i}}$ & $\sigma_{\mathrm{t}}^{\mathrm{d}} / \sigma_{\mathrm{ts}}^{\mathrm{i}}$ \\
\hline-2.0 & 3.7890 & 6.012 & 5.8930 & 2.7170 & 0.630 & 0.6430 \\
-1.5 & 3.9615 & 6.314 & 6.1035 & 2.8545 & 0.627 & 0.6491 \\
-1.0 & 4.1340 & 6.616 & 6.3140 & 2.9920 & 0.625 & 0.6547 \\
-0.5 & 4.3065 & 6.918 & 6.5245 & 3.1295 & 0.623 & 0.6601 & 1.387 \\
0.0 & 4.4790 & 7.220 & 6.7350 & 3.2670 & 0.620 & 0.6650 \\
0.5 & 4.6515 & 7.522 & 6.9455 & 3.4045 & 0.618 & 0.6697 \\
1.0 & 4.8240 & 7.824 & 7.1560 & 3.5420 & 0.616 & 0.6741 \\
\hline
\end{tabular}

of loadings, a comprehensive method can be obtained. The result of the indirect tensile test under the strip loading mode is ideal to reflect the tensile strength characteristics of a rock material. Therefore, according to the fitting formula of the three indirect tensile and direct tensile methods, the relationship between the three indirect tensile strengths and the direct tensile strength at 7 points in the range of the logarithm of the loading rate is discussed. It can be seen from Table 3 that the ratios of the direct tensile strength to the tensile strength of the arc loading, the plate loading, and the strip loading are $\sigma_{\mathrm{t}}^{\mathrm{d}} / \sigma_{\mathrm{tc}}^{\mathrm{i}}=0.623, \sigma_{\mathrm{t}}^{\mathrm{d}} / \sigma_{\mathrm{tp}}^{\mathrm{i}}=0.659$, and $\sigma_{\mathrm{t}}^{\mathrm{d}} / \sigma_{\mathrm{ts}}^{\mathrm{i}}=1.375$, respectively. However, considering the failure mode of the three indirect methods, the strip loading is more in line with the key factor of the central cracking. At the same time, the strength change rule under different loading rates is consistent with that under the direct tension condition. Therefore, the tension under strip loading can be used to characterize the direct tensile strength of a rock.

\section{Conclusions}

Based on the studies above, the following conclusions are obtained.

Whether in a direct tensile test or in one of the three different indirect tensile tests, the loading rate effects on the sandstone tensile strength objectively exist, i.e., the tensile strength of the sandstone increases with the loading rate. Moreover, at different loading rates, the rate of increase in the direct tensile strength is similar to that of the strength under the strip loading method. It is found that the tensile strengths under plate and arc loading are very close because the propagation of the cracks are restricted by the extrusion action of the plate and arc at the ends. The sandstone strength measured under strip loading is the lowest compared with those under other loadings because the propagation of the tensile cracks is accelerated by the local wedge expansion, which is similar to the strength under direct tension. However, a substantial difference still exists among the sandstone strengths measured from the three indirect tensile tests. Therefore, it is suggested that the specific test method should be indicated in future tensile strength test work. Because the failure mode of the strip loading is more consistent with the requirement of centralized crack initiation, the change rule at different loading rates is consistent with the change rule under direct tension. This paper recommends the strip loading method as an indirect approach to testing the tensile strength of rock.

In addition, the tests in this paper belong to the low loading rate. In the follow-up study, by using SHPB (Split Hopkinson Pressure Bar) test device [30], the dynamic 
tension test in high loading rate range can be carried out, and the differences of results obtained by different test methods can be compared and analysed.

\section{Data Availability}

The data used to support the findings of this study are included within the article.

\section{Conflicts of Interest}

The authors declare that they have no conflicts of interest.

\section{Acknowledgments}

This work was supported by the National Natural Science Foundation of China (Grant no. 41877272).

\section{References}

[1] A. P. Matthew and S. D. Mark, "A review of the tensile strength of rock: concepts and testing," Geotechnical and Geological Engineering, vol. 32, no. 2, pp. 525-546, 2014.

[2] H. Li, J. Li, B. Liu, J. Li, S. Li, and X. Xia, "Direct tension test for rock material under different strain rates at quasi-static loads," Rock Mechanics and Rock Engineering, vol. 46, no. 5, pp. 1247-1254, 2013.

[3] P. Pandey and D. P. Singh, "Deformation of a rock in different tensile tests," Engineering Geology, vol. 22, no. 3, pp. 281-292, 1986.

[4] V. P. Efimov, "The rock strength in different tension conditions," Journal of Mining Science, vol. 45, no. 6, pp. 569-575, 2009.

[5] K. Fuenkajorn and S. Klanphumeesri, "Laboratory determination of direct tensile strength and deformability of intact rocks," Geotechnical Testing Journal, vol. 34, no. 1, article 103134, 2011.

[6] T. Akazawa, "New test method for evaluating internal stress due to compression of concrete," Journal of Japan Society of Civil Engineers, vol. 29, pp. 777-787, 1943.

[7] E. M. R. Fairbairn and F.-J. Ulm, "A tribute to Fernando L. L. B. Carneiro (1913-2001) engineer and scientist who invented the Brazilian test," Materials and Structures, vol. 35, no. 3, pp. 195-196, 2002.

[8] A. Aydin and A. Basu, "The use of Brazilian Test as a quantitative measure of rock weathering," Rock Mechanics and Rock Engineering, vol. 39, no. 1, pp. 77-85, 2006.

[9] G. Barla and N. Innaurato, "Indirect tensile testing of anisotropic rocks," Rock Mechanics Felsmechanik M canique des Roches, vol. 5, no. 4, pp. 215-230, 1973.

[10] N. Erarslan and D. J. Williams, "Investigating the effect of cyclic loading on the indirect tensile strength of rocks," Rock Mechanics and Rock Engineering, vol. 45, no. 3, pp. 327-340, 2012.

[11] J. H. Ye, F. Q. Wu, and J. Z. Sun, "Estimation of the tensile elastic modulus using Brazilian disc by applying diametrically opposed concentrated loads," International Journal of Rock Mechanics \& Mining Sciences, vol. 46, no. 3, pp. 568-576, 2009.

[12] F.-Q. Gong and G.-F. Zhao, "Dynamic indirect strength of sandstone under different loading rates," Rock Mechanics and Rock Engineering, vol. 47, no. 6, pp. 2271-2278, 2014.

[13] F. Q. Gong, X. B. Li, and J. Zhao, "Analytical algorithm to estimate tensile modulus in Brazilian disk splitting tests," Chinese Journal of Rock Mechanics and Engineering, vol. 29, no. 5, pp. 881-891, 2010.
[14] ISRM, "Suggested methods for determining tensile strength of rock materials," International Journal of Rock Mechanics \& Mining Sciences, vol. 15, no. 3, pp. 99-103, 1978.

[15] ASTM C496-86, Standard Test Method for Splitting Tensile Strength of Cylindrical Concrete Specimens, ASTM International, West Conshohocken, PA, USA, 1986.

[16] The Professional Standard Compilation Group of People's Republic of China, SL264-2001. Specifications for Rock Tests in Water Conservancy and Hydroelectric Engineering, China Water Power Press, Beijing, China, 2001.

[17] D. Li and L. N. Y. Wong, "The Brazilian disc test for rock mechanics applications: review and new insights," Rock Mechanics and Rock Engineering, vol. 46, no. 2, pp. 269-287, 2013.

[18] S. H. Zhang, X. X. Miao, and H. Y. Zhao, "Influence of test methods on measured results of rock tensile strength," Journal of China University of Mining \& Technology, vol. 28, no. 3, pp. 243-246, 1999.

[19] Y. Yu, J. Zhang, and J. Zhang, "A modified Brazilian disk tension test," International Journal of Rock Mechanics and Mining Sciences, vol. 46, no. 2, pp. 421-425, 2009.

[20] F. Q. Gong, Experimental study of rock mechanical properties under coupled static-dynamic loads and dynamic strength criterion, Ph.D. thesis, Central South University, Changsha, China, 2010.

[21] D. Q. Dan, H. Konietzky, and M. Herbst, "Brazilian tensile strength tests on some anisotropic rocks," International Journal of Rock Mechanics and Mining Sciences, vol. 58, pp. 1-7, 2013.

[22] N. Erarslan and D. J. Williams, "Experimental, numerical and analytical studies on tensile strength of rocks," International Journal of Rock Mechanics and Mining Sciences, vol. 49, no. 1, pp. 21-30, 2012.

[23] L. Japaridze, "Stress-deformed state of cylindrical specimens during indirect tensile strength testing," Journal of Rock Mechanics and Geotechnical Engineering, vol. 7, no. 5, pp. 509-518, 2015.

[24] E. Kim and H. Changani, "Effect of water saturation and loading rate on the mechanical properties of Red and Buff Sandstones," International Journal of Rock Mechanics and Mining Sciences, vol. 88, pp. 23-28, 2016.

[25] M. A. Perras and M. S. Diederichs, "A review of the tensile strength of rock: concepts and testing," Geotechnical and Geological Engineering, vol. 32, no. 2, pp. 525-546, 2014.

[26] H. Zhao, Y. S. Yang, H. B. Xiao, C. Q. Zhang, and Y. P. Ya, "Research on loading rate effect of tensile strength property of hard brittle marble-test characteristics and mechanism," Chinese Journal of Rock Mechanics and Engineering, vol. 32, no. 9, pp. 1868-1874, 2013.

[27] J. Zhao and H. B. Li, "Experimental determination of dynamic tensile properties of a granite," International Journal of Rock Mechanics and Mining Sciences, vol. 37, no. 5, pp. 861-866, 2000.

[28] X. T. Zhang, Q. Y. Zhang, S. B. Yuan, C. Wang, and Q. Gao, "Development of test device for direct axial tension on rock and its application," Chinese Journal of Rock Mechanics and Engineering, vol. 33, no. 12, pp. 2517-2523, 2014.

[29] Q. Zhang, K. Duan, W. Xiang, S. Yuan, and Y.-Y. Jiao, “Direct tensile test on brittle rocks with the newly developed centering apparatus," Geotechnical Testing Journal, vol. 41, no. 1, article 20160301, 2017.

[30] F.-Q. Gong, X.-F. Si, X.-B. Li, and S.-Y. Wang, "Dynamic triaxial compression tests on sandstone at high strain rates and low confining pressures with split Hopkinson pressure bar," International Journal of Rock Mechanics and Mining Sciences, vol. 113, pp. 211-219, 2019. 


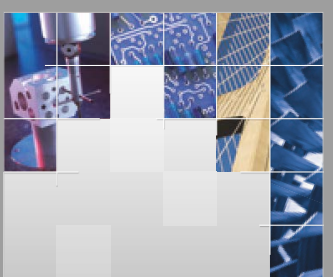

\section{Enfincering}
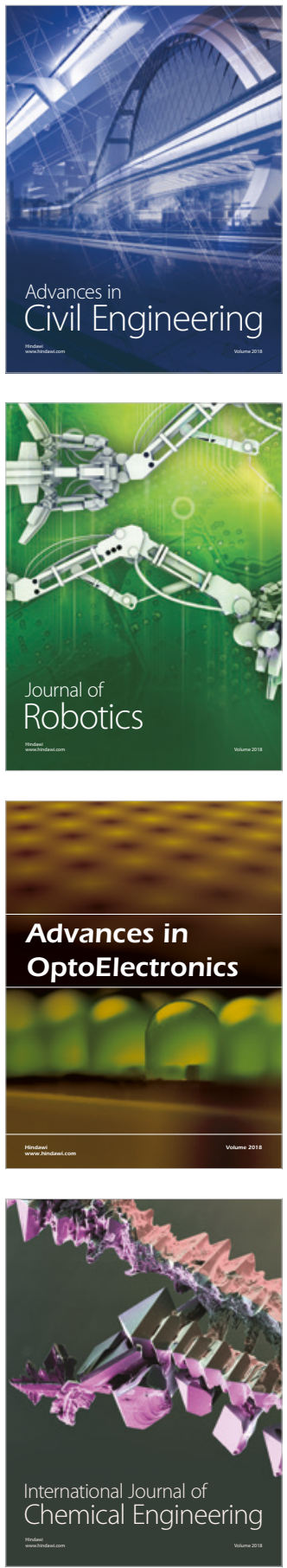

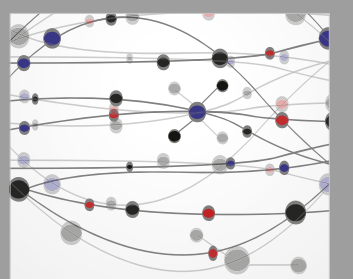

\section{Rotating \\ Machinery}

The Scientific World Journal

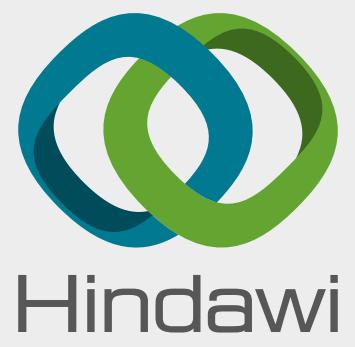

Submit your manuscripts at

www.hindawi.com
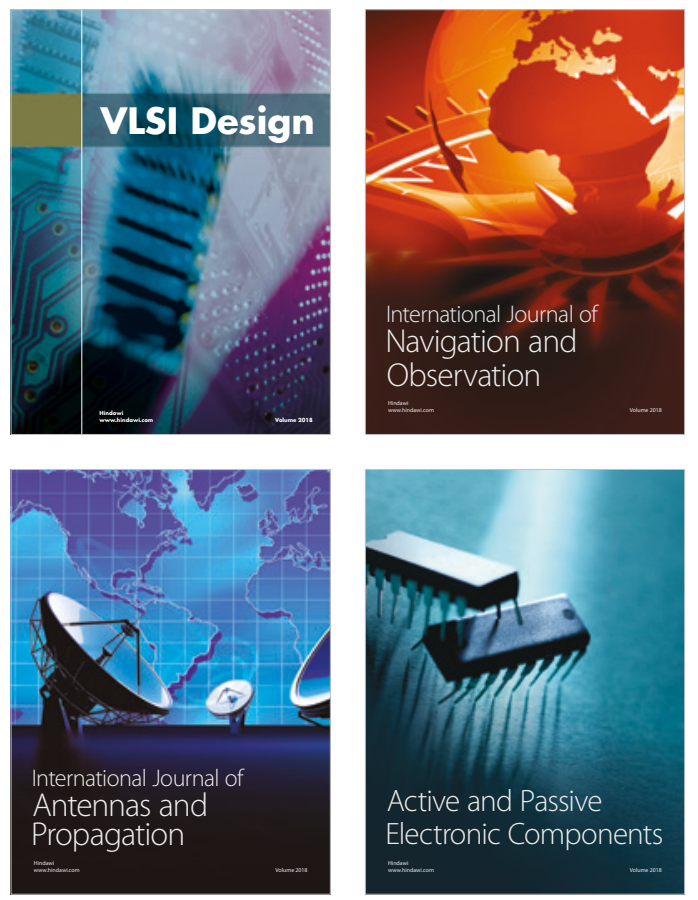
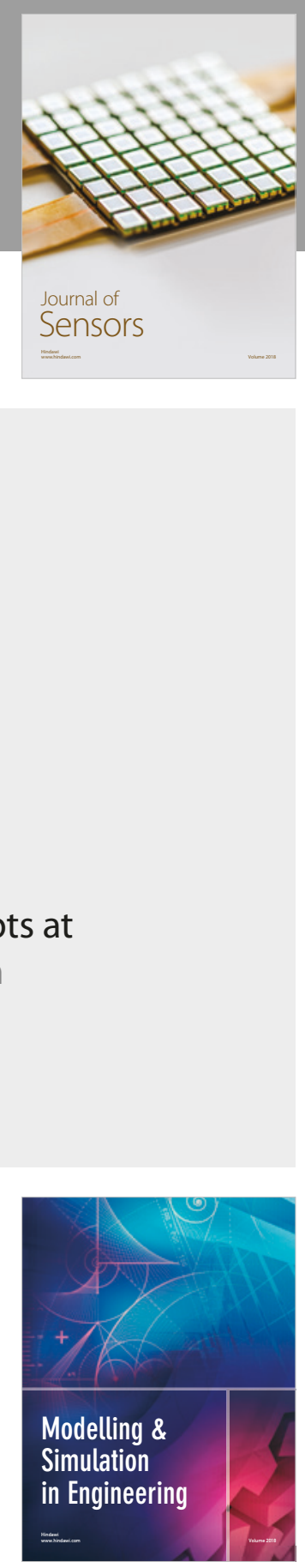

\section{Advances \\ Multimedia}
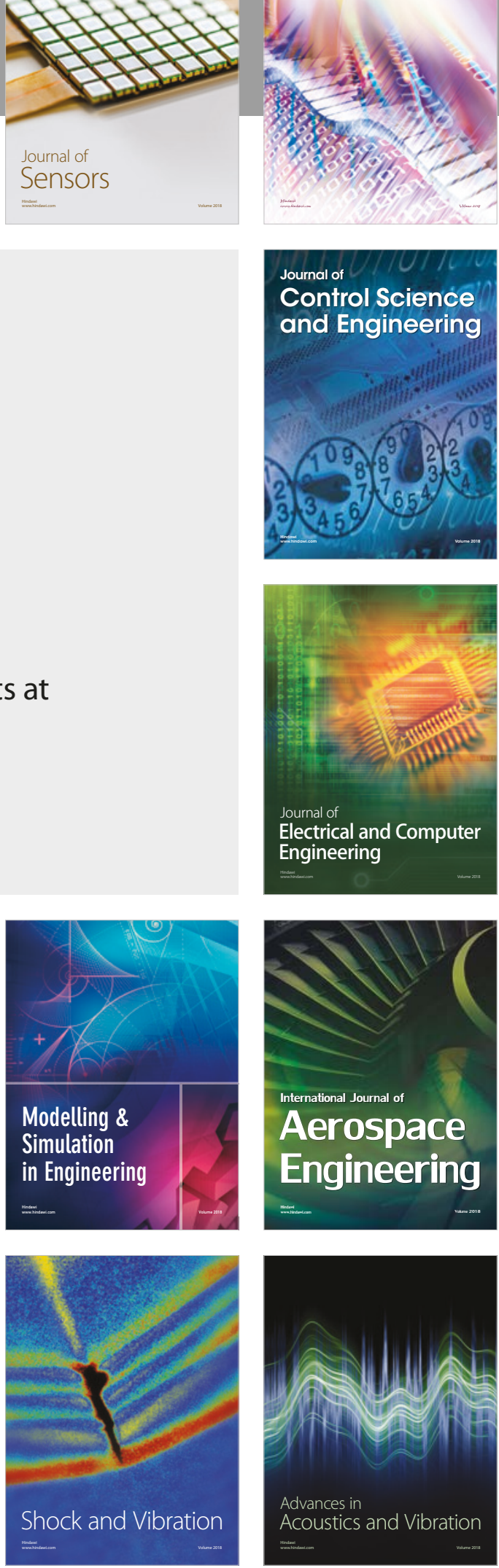